Check for updates

Cite this: RSC Adv., 2017, 7, 18861

Received 25th January 2017

Accepted 22nd March 2017

DOI: 10.1039/c7ra01146f

rsc.li/rsc-advances

\section{A spiro-centered thermopolymerizable fluorinated macromonomer: synthesis and conversion to the high performance polymer $\dagger$}

\begin{abstract}
Yuanqiang Wang, (D) Yijie Luo, (D) Kaikai Jin, Jing Sun and Qiang Fang (D) *
A new spiro-centered thermopolymerizable fluorinated macromonomer is reported here. This fourfunctional macromonomer is synthesized by a convergent strategy, and shows a low melting point $\left(93^{\circ} \mathrm{C}\right)$ and good solubility in the common organic solvents. When heated to a high temperature, the macromonomer converts into a cross-linked network $\left(\mathrm{PD}_{1}\right)$, which exhibits a $T_{\mathrm{g}}$ of near $316^{\circ} \mathrm{C}$ and a $5 \%$ weigh loss at a temperature of $417^{\circ} \mathrm{C}$ in $\mathrm{N}_{2}$. $\mathrm{PD}_{1}$ also shows a low dielectric constant $\left(D_{\mathrm{k}}=\right.$ 2.58 at $30 \mathrm{MHz}$ ) and high hydrophobicity (a water contact angle of $\theta=98^{\circ}$ ), as well as low water uptake (about $0.45 \%$, kept in boiling water for $72 \mathrm{~h}$ ). These results suggest that the macromonomer has a potential application in the production of the high performance polymers, in particular, it is very suitable for encapsulation resins or the coatings utilized in the microelectronics industry.
\end{abstract}

\section{Introduction}

High performance polymers have attracted much attention in past decades because of their excellent properties and wide applications in many areas of industry. ${ }^{\mathbf{1 - 1 0}}$ These materials usually show high thermostability, good mechanical properties, excellent insulating behavior and moisture resistance..$^{11-17}$ Therefore, they have played very important roles in the materials utilized in aerospace, electrical and microelectronics industries. However, most of the polymers show unsatisfactory processability, which needs to be improved. For example, a widely used polyimide with excellent thermostability and high strength, commercially known as Kapton, shows low solubility in the common organic solvents. ${ }^{18-20}$ Moreover, PEEKs, a class of engineering plastics having high $T_{\mathrm{g}}$ and high resistance to UV radiation exhibit high melting point and high melting viscosity. ${ }^{21,22}$ Hence, how to realize a balance between the processability and the high performance of the polymers is a challenging task.

In recent years, we are interested in developing the new materials with both high performance and good process-bility. ${ }^{12,23-26}$ It was found in our previous investigations that polymers or monomers with trifluorovinyl ether (TFVE) groups were more suitable for the preparation of the materials having both satisfactory physical properties and good processability. Those polymers or monomers usually showed good solubility in common organic solvents, as well as low melting point. Upon

Key Laboratory of Synthetic and Self-Assembly Chemistry for Organic Functional Molecules, Shanghai Institute of Organic Chemistry, Chinese Academy of Sciences, 345 Lingling Road, Shanghai 200032, PR China. E-mail: qiangfang@mail.sioc.ac.cn $\uparrow$ Electronic supplementary information (ESI) available: Experimental routes, NMR spectra of the monomers and polymers. See DOI: 10.1039/c7ra01146f heating, they easily converted to the crosslinked networks containing perfluorocyclobutane (PFCB) structure via thermally induced $[2+2]$ cyclodimerization of TFVE groups. ${ }^{27,28}$ The crosslinked networks exhibited good properties including high thermostability, good mechanical strength, low surface energy and dielectric constants, as well as highly visible transmittance. ${ }^{29-31}$ It is noted that spiro-centered polymers usually show high thermostability and good solubility owing to their rigid skeleton and distorted spiro-moiety. ${ }^{32,33}$ However, the dielectric properties of the spiro-centered polymers need to be improved. ${ }^{32,33}$ Based on the good dielectric properties of fluoropolymers, we have designed and synthesized a new functional monomer with spirophenol (S-1) as a core and thermocrosslinkable TFVE groups as the arms. The

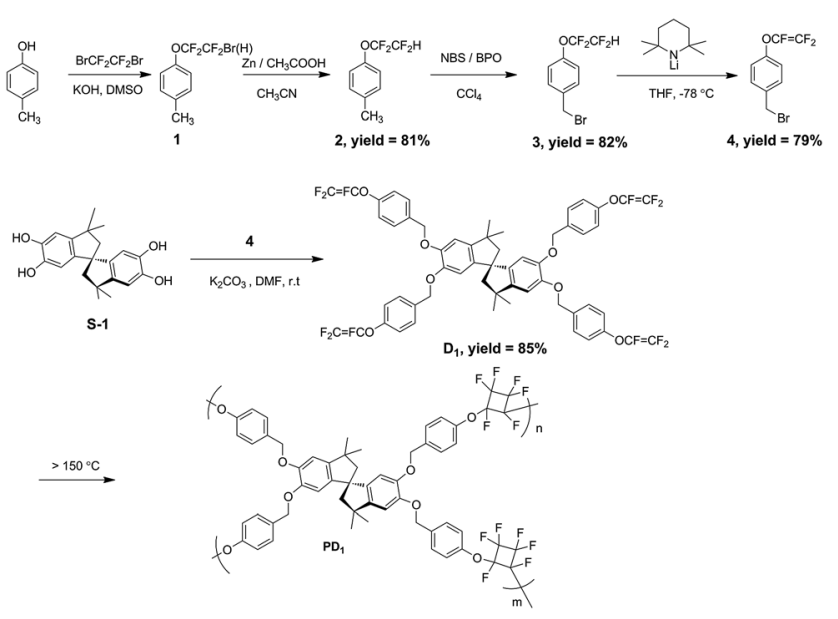

Scheme 1 Procedure for the synthesis and conversion of the new monomer $\mathrm{D}_{1}$. 
chemical structure of the monomer is depicted in Scheme 1. The monomer showed low melting point $\left(93^{\circ} \mathrm{C}\right)$ and good solubility in the common organic solvents. When heated at high temperature, the monomer transformed into a cross-linked network, which exhibited high $T_{\mathrm{g}}$ and low dielectric constant, as well as low water uptake. Those results indicate that the monomer can well realize the balance between the performance and processability of the polymers. Based on its good dielectric properties and thermostability, this monomer is very suitable as the encapsulation resin used in microelectronic industry, in which the high performance resins for sealing the devices are required. In particular, the resins with low dielectric constant, good processability, high thermostability and moisture-resistance are desirable.

\section{Results and discussion}

\section{Synthesis and characterization}

The procedure for the synthesis of the new monomer is shown in Scheme 1. By using a simple Williamson reaction between a spirophenol (S-1) and 1-(bromomethyl)-4-(trifluoroethenyloxy) benzene (compound $\mathbf{4}$ ), the new monomer $\mathbf{D}_{\mathbf{1}}$ was prepared in a high yield. Initially, we tried to synthesize compound 4 by using a general route. e.g., firstly, brominating compound 1 produced 1(bromomethyl)-4-(bromotrifluoroethyloxy)benzene, which was then treated with zinc to yield the target product via an elimination reaction. However, the bromomethyl $\left(-\mathrm{CH}_{2} \mathrm{Br}\right)$ group also reacted with zinc. Thus, compound $\mathbf{4}$ can not be prepared by using the conventional route. It is noted that a previous report offered a different route for the synthesis of compound 4 by using 4-bromophenol as the feedstock. ${ }^{34}$ Such a five-step procedure gave the product in low overall yield. In particular, dangerous tert-butyl lithium was used for the preparation of an intermediate, suggesting the route can not provide the product in large scale. ${ }^{34}$ Fortunately, when we tried to employ a new procedure proposed by our group, ${ }^{35}$ using lithium 2,2,6,6-tetramethylpiperidine (LTMP) as base to transform $-\mathrm{OCF}_{2} \mathrm{CF}_{2} \mathrm{H}$ into $-\mathrm{OCF}=\mathrm{CF}_{2}$, compound 4 was obtained in an overall yield of about $52 \%$, starting from 4-methylphenol. In that case, $-\mathrm{CH}_{2} \mathrm{Br}$ group in 3 did not reacted with LTMP. It must be pointed out that the reaction of spirophenol S-1 with compound $\mathbf{4}$ should be carried out in the presence of weaker bases at lower temperature because trifluorovinyl ether groups are sensitive to bases. We found that $\mathrm{K}_{2} \mathrm{CO}_{3}$ was a better base when the reaction was run at room temperature.

The new monomer $\mathbf{D}_{\mathbf{1}}$ was soluble in common organic solvents such as toluene, ethyl acetate and chloroform. When heated to near $100{ }^{\circ} \mathrm{C}$, the monomer melted and changed to a transparent liquid with very low viscosity, suggesting good processability of $\mathbf{D}_{\mathbf{1}}$.

The chemical structure of $\mathbf{D}_{\mathbf{1}}$ was characterized by its ${ }^{1} \mathrm{H}$ NMR, ${ }^{19} \mathrm{~F}$ NMR and ${ }^{13} \mathrm{C}$ NMR spectra, as well as by its elemental analysis results. The detailed data are listed in ESI. $\uparrow$ As depicted in the ESI, $\uparrow$ the signals, attributed to the $\mathrm{H}$ of $-\mathrm{CH}_{2} \mathrm{O}$ - groups, appear at 4.83-5.09 ppm in the ${ }^{1} \mathrm{H}$ NMR spectrum. Furthermore, the ${ }^{19} \mathrm{~F}$ NMR signals of $\mathbf{D}_{1}$ appearing at -119.35 to $-134.15 \mathrm{ppm}$, are ascribed to the $-\mathrm{OCF}=\mathrm{CF}_{2}$ groups. Thus, all detected data are accordance with the proposed structure.

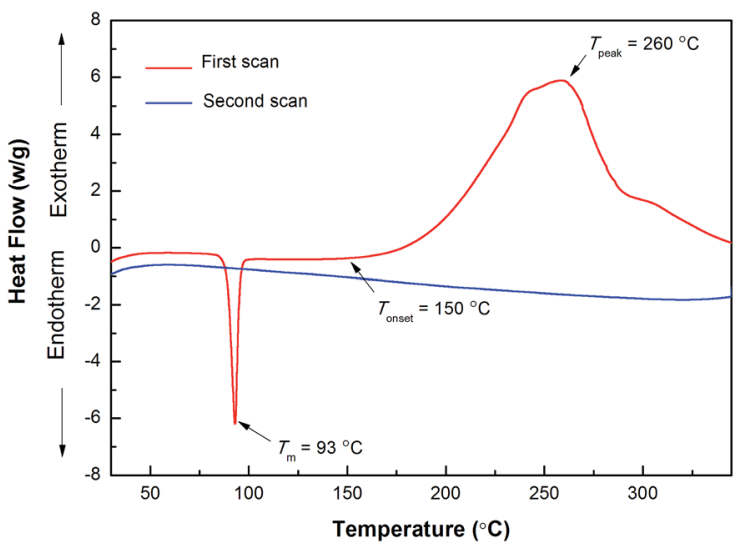

Fig. 1 DSC traces of $D_{1}$ at a heating rate of $10{ }^{\circ} \mathrm{C} \min ^{-1}$ in $N_{2}$ atmosphere.

\section{Thermo-crosslinking reaction}

Upon heating, $-\mathrm{OCF}=\mathrm{CF}_{2}$ groups have a tendency to form a crosslinking network via a $[2+2]$ cyclodimerization. In our case, the cyclodimerization process was monitored by differential scanning calorimetry (DSC), and the results are shown in Fig. 1. As depicted in Fig. 1, $\mathbf{D}_{1}$ exhibits a melting point at $93{ }^{\circ} \mathrm{C}$, and a curing onset temperature of about $150{ }^{\circ} \mathrm{C}$. With increasing temperature, the monomer gives a wide exothermic peak at a range of temperatures from 200 to $300{ }^{\circ} \mathrm{C}$, implying that $\mathbf{D}_{\mathbf{1}}$ has wide process windows. At second scan, no obvious exothermic peak is observed, meaning that the monomer has been completely converted.

The thermo-crossing degree of $\mathbf{D}_{\mathbf{1}}$ was characterized by FT-IR spectroscopy. Fig. 2 depicts the difference of FT-IR spectra between $\mathbf{D}_{\mathbf{1}}$ and thermo-crosslinked $\mathbf{D}_{\mathbf{1}}\left(\mathbf{P D}_{\mathbf{1}}\right)$. As can be seen form Fig. 2, a characteristic peak at $1835 \mathrm{~cm}^{-1}$ for TFVE disappears and a characteristic peak at $960 \mathrm{~cm}^{-1}$ for perfluorocyclobutane (PFCB) appears in $\mathbf{P D}_{\mathbf{1}}$.

\section{Thermostability and dielectric properties}

In many cases, thermo-crosslinking can effectively improve the heat-resistance of polymers. In our work, the

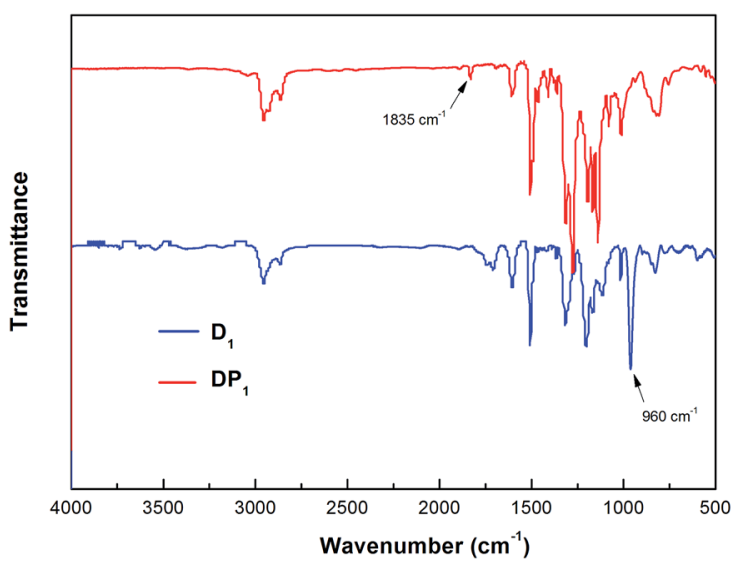

Fig. 2 FT-IR spectra of $D_{1}$ before (up) and after (down) thermocrosslinking. 
thermostability of thermo-crosslinked $\mathbf{D}_{\mathbf{1}}\left(\mathbf{P D}_{\mathbf{1}}\right)$ was investigated by thermal gravimetric analysis (TGA), and the results are shown in Fig. 3. As exhibited in Fig. 3, $\mathbf{P D}_{\mathbf{1}}$ has $5 \mathrm{wt} \%$ loss temperature of $417^{\circ} \mathrm{C}$ and a weight residue of $53 \%$ at $1000{ }^{\circ} \mathrm{C}$ (in $\mathrm{N}_{2}$ ), respectively. These data are higher than many commercial materials such as epoxy and phenolic resins. ${ }^{36,37}$ It is noted that coefficient of thermal expansion (CTE) reflects the dimensional stability of the materials upon the temperature changes. Fig. 4 depicts the CTE curves of $\mathbf{P D}_{\mathbf{1}}$ at a range of temperatures from 30 to $350{ }^{\circ} \mathrm{C}$. It is seen that $\mathbf{P D}_{\mathbf{1}}$ has an average linear CTE of $59.5 \mathrm{ppm}{ }^{\circ} \mathrm{C}^{-1}$ varying from 30 to $150{ }^{\circ} \mathrm{C}$, whereas such a value increases to $91.2 \mathrm{ppm}^{\circ} \mathrm{C}^{-1}$ when the temperature is up to $150^{\circ} \mathrm{C}$. Fig. 4 also gives a $T_{\mathrm{g}}$ value of $\mathbf{P D}_{1}$ (near $316{ }^{\circ} \mathrm{C}$ ), which is obviously higher than those of most phenolic and epoxy resins. ${ }^{36,37}$

The dielectric constant and dielectric loss of $\mathbf{P D}_{\mathbf{1}}$ were measured according to standard capacitance method, ${ }^{25}$ and the results are illustrated in Fig. 5. As can be seen from Fig. 5, the average dielectric constant of $\mathbf{P D}_{\mathbf{1}}$ is less than 2.58 , along with dissipation factor of below 0.01 varying from 1 to $30 \mathrm{~Hz}$. Such a low dielectric constant is attributed to the incorporation of $\mathrm{C}-\mathrm{F}$ bond, which decreases the polarity of the molecule. On the

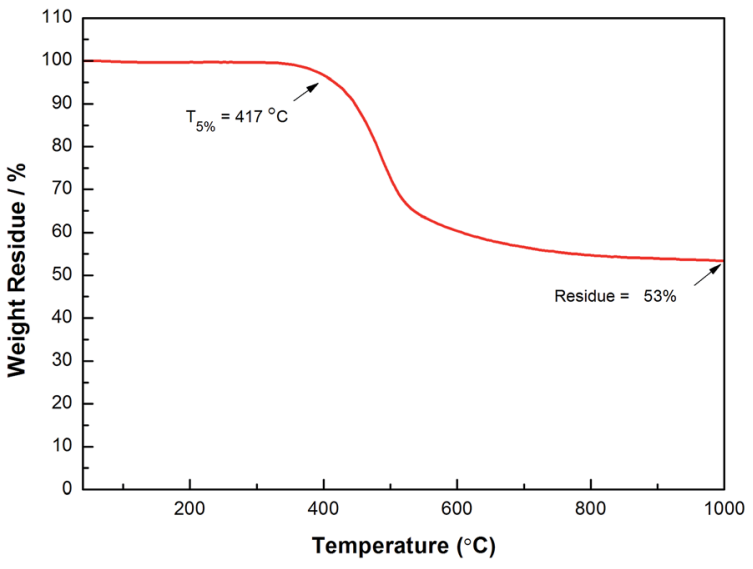

Fig. 3 TGA curves of $\mathrm{PD}_{1}$.

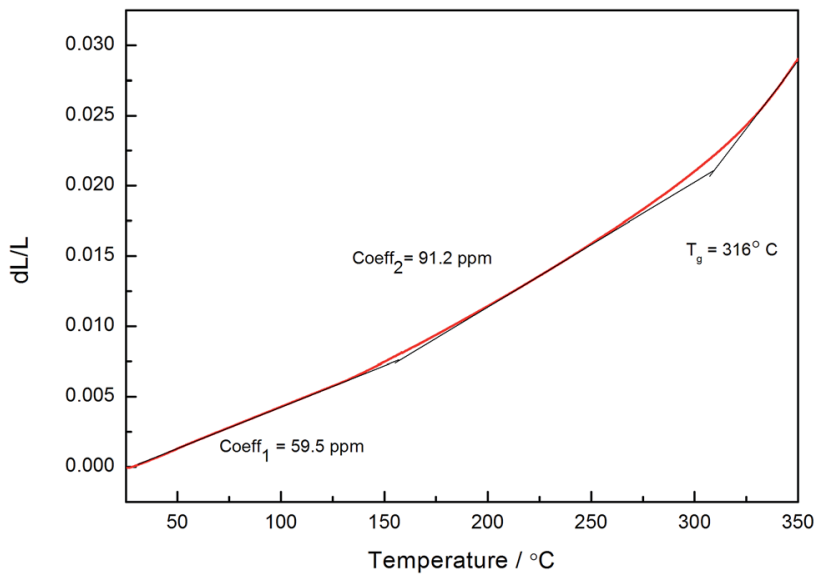

Fig. 4 Relative length change $(d L / L)$ of $P_{1}$ versus temperature $(T)$.

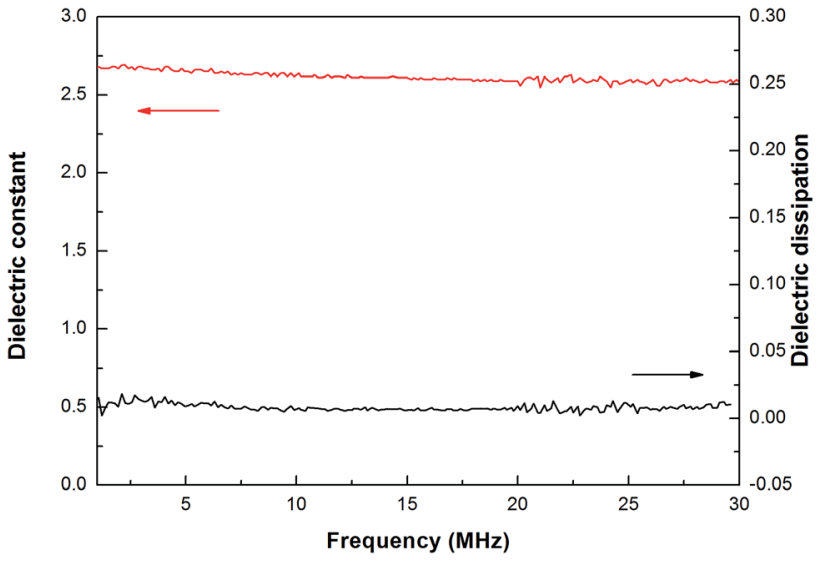

Fig. 5 Dielectric constant and dissipation factor of $\mathrm{PD}_{1}$ at different frequency at room temperature.

other hand, the formation of perfluorocyclobutane units during the curing of D1 can lower the crosslinking density, also resulting in the decreasing of dielectric constant. ${ }^{12}$ These results are comparable with that of commercial low-k materials, such as SILK (2.65-2.75), ${ }^{38}$ poly(aryl ether) (2.7-3.0), ${ }^{39}$ benzoxazine resins $(2.81),{ }^{40}$ and benzocyclobutene (BCB)-based polymers $(2.65){ }^{41}$

\section{Water uptake and film uniformity and mechanical properties}

It is very important to have low water absorption for the application of the materials in the microelectronic industry. The water uptake test of $\mathbf{P D}_{\mathbf{1}}$ was carried out in boiling water. After kept at the water for $72 \mathrm{~h}, \mathbf{P D}_{\mathbf{1}}$ showed water absorption of about $0.45 \%$. Such result is better than that of Kapton, a famous commercial polyimide used as the insulating coating in industry, which shows water absorption of $0.74 \%{ }^{42}$ In order to investigate the reason why $\mathbf{P D}_{\mathbf{1}}$ showed low water uptake, hydrophobicity of a $\mathbf{P D}_{\mathbf{1}}$ film also was surveyed by the water contact angle test. To obtain a film for the test, a solution of $\mathbf{D}_{\mathbf{1}}$ in 1,2,4-trimethylbenzene was heated at $180{ }^{\circ} \mathrm{C}$ for $4 \mathrm{~h}$ to give a pre-polymer. Spin-coating a solution of the pre-polymer on a silicon wafer gave a smooth and transparent film. The wafer was then moved to an oven, slowly heated to $220{ }^{\circ} \mathrm{C}$ and maintained at the temperature for $4 \mathrm{~h}$ in $\mathrm{N}_{2}$. Thus, a full cued $\mathbf{P D}_{1}$ film was obtained. On the surface of the film, the water contact angle was measured as $98.6^{\circ}$ (Fig. 6), indicating that the

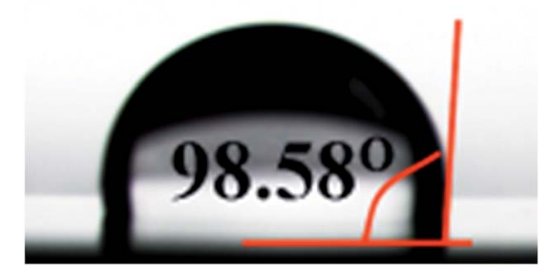

Fig. 6 Contact angle of water on a $\mathrm{PD}_{1}$ film. 


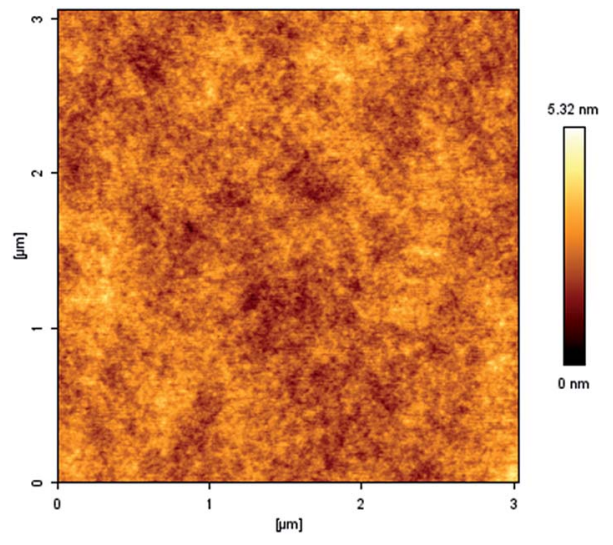

Fig. 7 AFM image of $P D_{1}$.

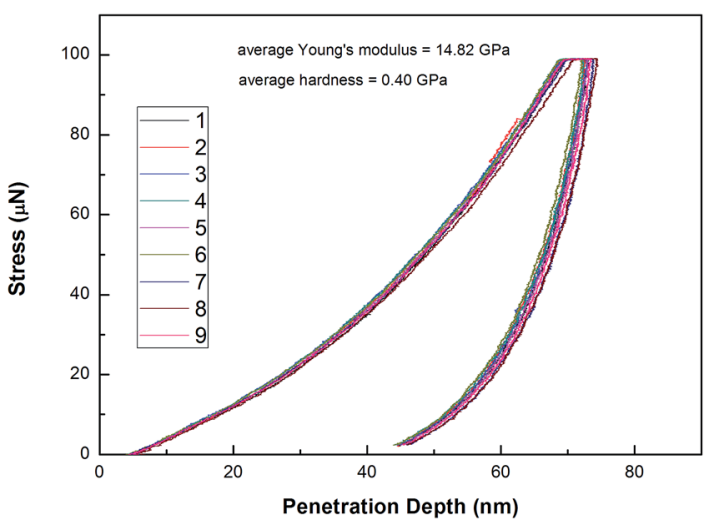

Fig. 8 The load-displacement curves of nanoindentation tests for a $\mathrm{PD}_{1}$ film.

$\mathbf{P D}_{1}$ film has good hydrophobicity. Thus, the low water uptake of $\mathbf{P D}_{\mathbf{1}}$ is attributed to the high hydrophobicity of the polymer.

The film uniformity of $\mathbf{P D}_{\mathbf{1}}$ was characterized by means of atomic force microscopy (AFM). Fig. 7 exhibits the AFM image of the surface of a $\mathbf{P D}_{\mathbf{1}}$ film on a silicon wafer. In a $3.0 \times 3.0 \mu \mathrm{m}$ area, the average surface roughness $\left(R_{\mathrm{a}}\right)$ of $\mathbf{P D}_{\mathbf{1}}$ film is about $0.34 \mathrm{~nm}$. Such a low $R_{\mathrm{a}}$ value suggests that $\mathbf{P D}_{\mathbf{1}}$ film have good uniformity.

The nano indenter/scratch system was used to measure the mechanical properties of $\mathbf{P D}_{\mathbf{1}}$, (as shown in Fig. 8 and Tables S1, S2 $\dagger$ ). The results indicated that a $\mathbf{P D}_{\mathbf{1}}$ film had an average hardness of $0.41 \mathrm{GPa}$, a Young's modulus of 14.82 GPa and a bonding strength to the silicon wafer of $0.23 \mathrm{GPa}$, respectively. These data exhibit that $\mathbf{P D}_{\mathbf{1}}$ is suitable as a high performance coating utilized in electronic/electrical devices.

\section{Conclusions}

In summary, we have successfully synthesized a new tetrafunctional macromonomer by using a facile procedure. This macromonomer shows low melting point $\left(93{ }^{\circ} \mathrm{C}\right)$ and good solubility in the common organic solvents. The monomer can be easily thermally transformed into a cross-linked network, showing high $T_{\mathrm{g}}$, low dielectric constant, good film uniformity and low water absorption. These good properties suggest the monomer is very suitable as the encapsulation resins or the coatings utilized in microelectronic industry.

\section{Acknowledgements}

Financial supports from Ministry of Science and Technology of China (2015CB931900) and the Natural Science Foundation of China (NSFC No. 21574146 and No. 21504103) and the Science and Technology Commission of Shanghai Municipality (15ZR1449200 and 16JC1403800) are gratefully acknowledged. The authors are also grateful to the Strategic Priority Research Program of the Chinese Academy of Sciences (Grant XDB 20020000).

\section{Notes and references}

1 F. Herold and A. Schneller, High-Performance Polymers, $A d v$. Mater., 1992, 4, 143-152.

2 X. Guo, R. P. Ortiz, Y. Zheng, M.-G. Kim, S. Zhang, Y. Hu, G. Lu, A. Facchetti and T. J. Marks, Thieno[3,4-c]pyrrole4,6-dione-based Polymer Semiconductors: Toward HighPerformance, Air-Stable Organic Thin-Film Transistors, $J$. Am. Chem. Soc., 2011, 133, 13685-13697.

3 J. K. Fink, High performance polymers, William Andrew Inc., New York, 2008.

4 M. G. Dhara and S. Banerjee, Fluorinated High-Performance Polymers: poly(arylene ether)s and Aromatic Polyimides Containing Trifluoromethyl Groups, Prog. Polym. Sci., 2010, 35, 1022-1077.

5 T. M. Swager, Iptycenes in the Design of High Performance Polymers, Acc. Chem. Res., 1994, 41, 1181-1189.

6 R. B. Seymour, Advances in High-Performance Polymers, in The Effects of Hostile Environments on Coatings and Plastics, ACS Symp Ser, 229, ed. D. P. Garner1 and G. Allan Stahl, American Chemical Society, Washington, DC, 1983, pp. 8798.

7 D. K. Dei, B. R. Lund, J. Wu, D. Simon, T. Ware, W. E. Voit, D. MacFarlane, S. M. Liff and D. W. Smith, High Performance and Multipurpose Triarylamine-Enchained Semifluorinated Polymers, ACS Macro Lett., 1989, 2, 35-39.

8 T. Lei, Y. Cao, Y. Fan, C.-J. Liu, S.-C. Yuan and J. Pei, HighPerformance Air-Stable Organic Field-Effect Transistors: Isoindigo-Based Conjugated Polymers, J. Am. Chem. Soc., 1989, 133, 6099-6101.

9 H. Hatakeyama, S. Hirose and T. Hatakeyama, HighPerformance Polymers from Lignin Degradation Products, in Lignin: properties and materials, ACS Symp Ser, 397, ed. W. G. Glasser and S. Sarkane, American Chemical Society, Washington, DC, 1989, pp. 205-218.

10 T. Shimomura and T. Namba, Preparation and Application of High-Performance Superabsorbent Polymers, in Superabsorbent Polymers, ACS Symp Ser, 573, ed. F. L. Buchholz1 and N. A. Peppas, American Chemical Society, Washington, DC, 1994, pp. 112-127. 
11 H.-C. Liou, P. S. Ho and A. McKerrow, The effect of crosslinking on aromatic ether polymers, J. Polym. Sci., Part B: Polym. Phys., 1998, 36, 1383-1392.

12 C. Yuan, K. Jin, K. Li, S. Diao, J. Tong and Q. Fang, NonPorous Low-k Dielectric Films Based on a New Structural Amorphous Fluoropolymer, Adv. Mater., 2013, 25, 48754878.

13 Y. Luo, J. Sun, K. Jin, J. Wang, G. Huang and Q. Fang, Propargyl ether-functionalized poly(m-phenylene): a new precursor for the preparation of polymers with high modulus and high $T_{\mathrm{g}}, R S C$ Adv., 2015, 5, 23009-23014.

14 M. Pantouvaki, C. Huffman, L. Zhao, N. Heylen, Y. Ono, M. Nakajima, K. Nakatani, G. P. Beyer and M. R. Baklanov, Jpn. Advanced Organic Polymer for the Aggressive Scaling of Low-k Materials, J. Appl. Phys., 2011, 50, 584-587.

15 D. Shamiryan, T. Abell, F. Iacopi and K. Maex, Low-k dielectric materials, Mater. Today, 2004, 7, 34-39.

16 R. Souzy, B. Ameduri and B. Boutevin, Synthesis and copolymerization of monofluoro, difluoro, trifluorostyrene and ((trifluorovinyl)oxy)benzene, Prog. Polym. Sci., 2004, 29, 75-106.

17 C. A. Corley, A. J. Guenthner, C. M. Sahagun and K. R. Lamison, Di(cyanate Ester) Networks Based on Alternative Fluorinated Bisphenols with Extremely Low Water Uptake, ACS Macro Lett., 2014, 3, 105-109.

18 J. M. García, F. C. García, F. Serna and J. L. de la Peña, Highperformance aromatic polyamides, Prog. Polym. Sci., 2010, 35, 623-686.

19 D.-J. Liaw, K.-L. Wang, Y.-C. Huang, K.-R. Lee, J.-Y. Lai and C.-S. Ha, Advanced polyimide materials: Syntheses, physical properties and applications, Prog. Polym. Sci., 2012, 37, 907-974.

20 M. G. Dhara and S. Banerjee, Fluorinated high-performance polymers: Poly(arylene ether)s and aromatic polyimides containing trifluoromethyl groups, Prog. Polym. Sci., 2010, 35, 1022-1077.

21 H. X. Guyen and H. Ishida, Poly(aryl-ether-ether-ketone) and its advanced composites: a review, Polym. Compos., 1987, 8, $57-73$.

22 S. Pramanik and K. K. Kar, Functionalized poly(ether ether ketone): improved mechanical property and acellular bioactivity, J. Appl. Polym. Sci., 2012, 123, 1100-1111.

23 J. Wang, K. Li, C. Yuan, K. Jin, S. Tian, J. Sun and Q. Fang, Variable Polymer Properties Driven by Substituent Groups: Investigation on a Trifluorovinylether- Functionalized Polyfluorene at the C-9 Position, Macromol. Chem. Phys., 2015, 216, 742-748.

24 C. Yuan, J. Wang, K. Jin, S. Diao, J. Sun, J. Tong and Q. Fang, Postpolymerization of Functional Organosiloxanes: An Efficient Strategy for Preparation of Low-k Material with Enhanced Thermostability and Mechanical Properties, Macromolecules, 2014, 47, 6311-6315.

25 F. He, Y. Gao, K. Jin, J. Wang, J. Sun and Q. Fang, Conversion of a Biorenewable Plant Oil (Anethole) to a New Fluoropolymer with Both Low Dielectric Constant and Low Water Uptake, ACS Sustainable Chem. Eng., 2016, 4, 44514456.
26 J. Zhou, L. Fang, J. Wang, J. Sun, K. Jin and Q. Fang, Postfunctionalization of novolac resins by introducing thermocrosslinkable $-\mathrm{OCF}=\mathrm{CF} 2$ groups as the side chains: a new strategy for production of thermosetting polymers without releasing volatiles, Polym. Chem., 2016, 7, 4313-4316.

27 S. T. Iacono, S. M. Budy, J. Jin and D. W. Smith Jr, Science and technology of perfluorocyclobutyl aryl ether polymers, J. Polym. Sci., Part A: Polym. Chem., 2007, 45, 5705-5721.

28 D. A. Babb, B. R. Ezzell, K. S. Clement, W. F. Richey and A. P. Kennedy, Perfluorocyclobutane aromatic ether polymers, J. Polym. Sci., Part A: Polym. Chem., 1993, 31, 3465-3477.

29 M. Mujkic, S. T. Iacono, A. R. Neilson and D. W. Smith Jr, Recent Optical Applications of Perfluorocyclobutyl Aryl Ether Polymers, Macromol. Symp., 2009, 283-284, 326-335.

30 R. Verma, S. Creager, J. Ballato and D. W. Smith Jr, Optimized statically non-wetting hydrophobic electrospun surface of perfluorocyclobutyl aryl ether polymer, Polym. Int., 2013, 62, 1152-1158.

$31 \mathrm{H}$. Pu, Fluoropolymers for Proton Exchange Membranes, in Polymers for PEM Fuel Cells, John Wiley \& Sons, Inc., 2014, pp. 50-101.

32 N. K. Sini, M. Azechi and T. Endo, Synthesis and Properties of Spiro-Centered Benzoxazines, Macromolecules, 2015, 48, 7466-7472.

33 C. R. Mason, L. Maynard-Atem, K. W. J. Heard, B. Satilmis, P. M. Budd, K. Friess, M. Lanc, P. Bernardo, G. Clarizia and J. C. Jansen, Enhancement of $\mathrm{CO}_{2}$ Affinity in a Polymer of Intrinsic Microporosity by Amine Modification, Macromolecules, 2014, 47, 1021-1029.

34 B. K. Spraul, S. Suresh, J. Jin and D. W. Smith Jr, Synthesis and Electronic Factors in Thermal Cyclodimerization of Functionalized Aromatic Trifluorovinyl Ethers, J. Am. Chem. Soc., 2006, 128, 7055-7064.

35 Y. Luo, K. Jin, C. He, J. Wang, J. Sun, F. He, J. Zhou, Y. Wang and Q. Fang, An Intrinsically Microporous Network Polymer with Good Dielectric Properties at High Frequency, Macromolecules, 2016, 49, 7314-7321.

36 H. J. Hwang, S. W. Hsu, C. L. Chung and C.-S. Wang, Low dielectric epoxy resins from dicyclopentadiene-containing poly(phenylene oxide) novolac cured with dicyclopentadiene containing epoxy, React. Funct. Polym., 2008, 68, 1185-1193.

37 A. Knop and L. A. Pilato, Phenolic Resins: Chemistry, Applications and Performance, Springer-Verlag, Berlin Heidelberg, 1985.

38 S. J. Martin, J. P. Godschalx, M. E. Mills, E. O. Shaffer II and P. H. Townsend, Development of a low-dielectric-constant polymer for the fabrication of integrated circuit interconnect, Adv. Mater., 2000, 12, 1769-1778.

39 C. Wang, C. Xu, Q. Li, W. Chen and X. Zhao, Synthesis of new fluorene-based poly(aryl ether) containing pendant tert-butyl groups for low dielectric materials, Colloid Polym. Sci., 2015, 293, 313-318.

40 J. Wu, Y. Xi, G. T. McCandless, Y. Xie, R. Menon, Y. Patel, D. J. Yang, S. T. Iacono and B. M. Novak, Synthesis and Characterization of Partially Fluorinated Polybenzoxazine 
Resins Utilizing Octafluorocyclopentene as a Versatile Building Block, Macromolecules, 2015, 48, 6087-6095.

41 J. Tong, S. Diao, K. Jin, C. Yuan, J. Wang, J. Sun and Q. Fang, Benzocyclobutene-functionalized poly(m-phenylene): a novel polymer with low dielectric constant and high thermostability, Polymer, 2014, 55, 3628-3633.

42 F. Bellucci and L. Nicodemo, Water transport in organic coatings, Corros. Sci., 1993, 49, 235-247. 